\title{
Sustitución de Importaciones e Industrialización. Desde el siglo XX hasta al Socialismo del Siglo XXI, caso Ecuador
}

\author{
Imports Substitution and Industrialization. From the 20th century to \\ the Socialism of the 21st century, Ecuador case
}

\author{
Christian Paúl Naranjo Navas \\ Universidad Nacional de Chimborazo (Ecuador) \\ paulnaranjo@outlook.com
}

\begin{abstract}
Resumen
Los modelos de crecimiento e industrialización de la CEPAL, en la década de los cincuenta y sesenta, y de Ecuador, a través del movimiento del Socialismo del Siglo XXI, se asemejan en el intento de industrialización a través de la sustitución de importaciones. En este contexto, el objetivo primario de esta investigación es revisar las similitudes e incompatibilidades del proceso "cepalino" y el gobierno de Rafael Correa a través de una metodología comparativa cuantitativa, entendida dentro de los contextos históricos de ambos procesos. La investigación concluye que, en ambos casos, los modelos produjeron problemas similares, a saber: problemas en la balanza de pagos; y, una creciente deuda pública. El caso ecuatoriano presenta un elemento exclusivo, la moneda oficial es el dólar estadounidense, lo que sugiere que la masa monetaria depende directamente del ingreso de dólares a la economía.
\end{abstract}

\section{Palabras clave}

ISI, industrialización; sustitución de importaciones; CEPAL; Ecuador; socialismo del siglo XXI.

\begin{abstract}
The growth and industrialization models of ECLAC, in the 1950s and 1960s, and of Ecuador, through the movement of Socialism of the 21st Century, are similar in the attempt of industrialization through import substitution. In this context, the primary objective of this research is to review the similarities and incompatibilities of the ECLAC process and the government of Rafael Correa through a quantitative comparative methodology, understood within the historical contexts of both processes. The investigation concludes that, in both cases, the models produced similar problems, meaning: problems in the balance of payments; and, a growing public debt. The Ecuadorian case presents an exclusive element, the official currency is the US dollar, which suggests that the money supply depends directly on the entry of dollars into the economy.
\end{abstract}

\section{Keywords}

ISI; industrialization; import substitution; ECLAC; Ecuador; socialism of the 21st century. 


\section{Christian Paúl Naranjo Navas}

\section{Introducción}

América Latina ha repensado constantemente el papel del gasto público en el crecimiento económico de las naciones. El papel del gasto público se convierte en una de las piedras angulares del desarrollo regional, especialmente a partir de la aplicación de políticas económicas estructuradas en la Comisión Económica para América Latina y el Caribe, CEPAL, especialmente durante la etapa de Industrialización y Sustitución de Importaciones, ISI. De acuerdo a Jeffry Frieden (2006), aunque algunos países, como Brasil y Argentina, experimentaron procesos de industrialización, el modelo no fue sostenible por dos razones: la primera, la creciente inestabilidad en la balanza comercial causada por las nuevas industrias, las cuales necesitaban de insumos como materia prima, maquinaria o material para reparaciones; segundo, la creciente deuda pública que apoyaba los programas de infraestructura que requerían los nuevos planes de industrialización de las naciones.

Un modelo similar a la Industrialización y Sustitución de Importaciones fue instaurado por el gobierno de Rafael Correa, a través del movimiento político Revolución Ciudadana. El gobierno ecuatoriano instauró un proceso similar a la ISI a través de un incremento en el gasto público y a través del plan denominado "cambio de la matriz productiva". Los resultados del régimen se asemejan a los resultados de la ISI, a decir, un desequilibrio de la balanza de pagos; $y$, una creciente deuda pública. Sin embargo, el desequilibrio de la balanza de pagos no fue causada por el creciente número de la producción industrias que urgían por un contante flujo de insumos, como lo muestra la fluctuación de la tasa de crecimiento manufactura, la cual, en promedio, se mantuvo en índices similares hasta el 2013 (figura 4), y luego decreció hasta el 2017.

Si bien los modelos se asemejan de forma importante, el artículo analiza dos elementos que son exclusivos del tiempo del presidente Rafael Correa. Primero, Ecuador no cuenta con una moneda propia, sino que, desde enero de 2000, su moneda nacional es el dólar estadounidense. Segundo, la masa monetaria depende directamente del ingreso de dólares a la economía. Estos dos elementos, relacionados estrechamente, hacen del caso ecuatoriano un caso de estudio diferente a los otros casos del socialismo del siglo XXI. De esta forma, los objetivos primarios de esta investigación son; primero, revisar las similitudes e incompatibilidades del proceso "cepalino" y el gobierno de Rafael Correa; segundo, analizar el modelo ecuatoriano, tomando en cuenta la relación entre el dólar y la oferta monetaria.

\section{Modelo Cepalino: Industrialización y Sustitución de Importaciones}

El modelo Cepalino comprende la respuesta a la dependencia del mercado externo, como un escudo de protección contra las vicisitudes de los ciclos económicos 


\section{Sustitución de Importaciones e Industrialización. Desde el siglo XX hasta al Socialismo del Siglo XXI, caso Ecuador}

internacionales. De acuerdo Furtado (1970), Pinto (1969) y Prebisch (1969), la integración con el mercado mundial abrió el espacio para que los problemas del mercado externo afectaran las economías de los países en vías de desarrollo. Este problema fue evidente durante la Gran Depresión, crisis que devastó el sector exportador de América Latina y puso en crisis los modelos de desarrollo concebidos hasta entonces. En este contexto, Tavares (1969), citado por Vallejo (2003), señala que las exportaciones eran, hasta 1929, el eje central del crecimiento de la región latinoamericana, mientras que las importaciones sirvieron para la adquisición de bienes de consumo final, y un pequeño porcentaje para bienes intermedios y bienes de capital.

El problema central se enfocó en los términos de intercambio, a decir: en el tiempo, los precios de los bienes manufacturados crecieron en una tasa más alta que los precios de las materias primas y productos agrícolas, lo que significó, a largo plazo, que la brecha entre países desarrollado y los países en vías de desarrollo se ampliara en el tiempo. Prebisch (1998), citado por Martinez Casas \& Guzman (2011), presenta la hipótesis de que, de 1876 1947, de que se presenta un tendencia al deterioro de los términos de intercambio, dejando los productos primarios cada vez más por detrás de los producto manufacturados, "la relación de precios se ha movido, pues, en forma adversa a la periferia; contrariamente a los que hubiera sucedido, si los precios hubiesen declinado conforme al descenso de costo provocado por el aumento de productividad" (Martinez Casas \& Guzman, 2011, p. 77). Esta primera hipótesis fue luego corroborada por Ocampo y Parra (2003), quienes realizan un análisis estadístico de 24 productos básicos entre 1900 y 2000. En su investigación, los autores concluyen que hubo un deterioro de los términos de intercambio, una caída de alrededor de $1 \%$ anual.

La respuesta al problema de la diferencia de los términos de intercambio se visualizó en el crecimiento hacia adentro. La ISI se concentró, entonces, en la industrialización a través del crecimiento industrial desde adentro, cuya producción podía consumirse a nivel interno o externo. Esta idea gobernó gran parte de América Latina desde 1930 hasta finales de 1970 (Bonfanti, 2015). La ISI no se implementó en la región al mismo tiempo, sino, por el contrario, los grandes centros urbanos fueron los primeros en implementar las políticas de la ISI, como Brasil, Argentina, Chile y México. La primera etapa de la ISI corresponde a un fuerte sistema de restricciones a las importaciones, además del apoyo el proceso sustitutivo a través del manejo del tipo de cambio y de las políticas de restricciones de ingreso (Gonzáles Arévalo, 2010). En los siguientes apartados se analizará los logros y problemas más importantes de la implementación del programa de la ISI en algunos países de América Latina.

Después de la década de los 70s, los modelos de desarrollo de la CEPAL pasaron por al menos cuatro etapas (CEPAL, 2014). Durante la década de los 70s, se enfoca en la estructura productiva y distributiva y procesos de industrialización que combinan el mercado interno y el sector exportador. A partir de los 80s, la región tuvo que enfrentar la crisis de la deuda, devenida de los modelos previos, en esta etapa, la 


\section{Christian Paúl Naranjo Navas}

CEPAL se concentró en el ajuste con crecimiento, evitando los choques sociales. En la década de los 90s, la CEPAL se concentró en la transformación productiva con equidad dada la vulnerabilidad a los movimientos de capitales. Finalmente, a partir de la primera década del segundo milenio, el enfoque se desplazó a la inestabilidad macroeconómica, bajo dinamismo económico y efectos sociales adversos; así, se propone la corrección de las asimetrías macroeconómicas y financieras internacionales, el fortalecimiento institucional a través de agencias reguladoras y pactos sociales eficientes, una visión amplia de la estabilidad macroeconómica, y estrategias de desarrollo productivo.

\section{Programas de industrialización}

La Industrialización por Sustitución de Importaciones no fue el primer proceso de industrialización de América Latina, la cual siguió un curso espontáneo a partir de los intereses privados de los sectores estratégicos como el exportador, las comunicaciones y la modernización del estado. Esta primera industrialización vino de la mano de la modernización institucional a través de la visita de Misión Kemmerer; de la mano del desarrollo de la infraestructura y comunicaciones en sectores como el ferroviario y eléctrico; y la expansión de la industria impulsada por productos como cacao, café y textiles (Colombia, Ecuador), nitrato (Chile), fabricación de electrodomésticos y montaje de vehículos de motor (Chile, Uruguay) o producción ganadera (Argentina). La diferencia, esta vez, fue que, se introducía la intervención activa del gobierno de forma planificada. El programa de industrialización propuso tres enfoques centrales Colin (2019, p. 9): la industrialización como pilar del desarrollo; una expansión considerable del alcance de la acción estatal en los asuntos económicos y sociales; y un patrón de producción orientado hacia el mercado interno.

Los programas de industrialización en América Latina tuvieron varias etapas (Bonfanti, 2015). Una primera etapa se caracterizó por una protección fuerte a la producción nacional. Esta etapa trajo consigo el aumento del consumo interno. Una segunda etapa, contextualizada en la década de los cincuenta hasta los setenta, se visualizó un gran desarrollo de la producción industrial, sobre todo de la producción de la manufactura (figura 1). No obstante, a finales de la década de los sesenta, el sector industrial empieza a mostrar signos de debilidad, lo que llevo a las naciones a una mayor protección de la oferta interna. En esta temporalidad, las empresas transnacionales trasladaron la toma de decisiones al exterior. En la tercera etapa, se extiende durante la década de los setenta, hasta principios de los ochenta, dependiendo el país que se analice. En esta etapa, las fallas estructurales se agudizaron de forma profunda. La nueva industria produjo escuetamente bienes de capital, lo que agudizó el problema de la balanza de pagos.

Las economías más grandes de América del Sur tuvieron una de las tasas de recuperación industrial más impresionantes entre finales del siglo XIX y finales de 


\section{Sustitución de Importaciones e Industrialización. Desde el siglo XX hasta al Socialismo del Siglo XXI, caso Ecuador}

la década de 1970 (Bénétrix, O’Rourke, \& Williamson, 2012). Varios países de América Latina intentaron implementar planes de industrialización, los países de mayor desarrollo industrial fueron Brasil, México, Colombia, Argentina, Chile y Uruguay. Este grupo de países, LA6, aunque entre ellos, los de mayor desarrollo fueron Brasil, México y Colombia (figura 1). Bulmer-Thomas (2007), señala que, mientras algunos países se subieron en la ola de la industrialización por sustitución de importaciones, otros países, como en el caso de Perú, se quedaron estancados por limitaciones políticas. En el caso de Venezuela, quien vio el surgimiento de cierta manufactura moderna fue posible a través del crecimiento de los ingresos petroleros. En el caso de Ecuador, el intento de industrialización fue tardío y vino de la mano del boom petrolero de los 70s. A razón de los pocos estudios del caso ecuatoriano, se ha preferido dejarlo de lado, esperando trabajar en ello en próximas investigaciones.

Figura 1. Índices de producción industrial en el sector manufacturero para Argentina, Brasil, Colombia y Chile, 1950-1990, 1958=100

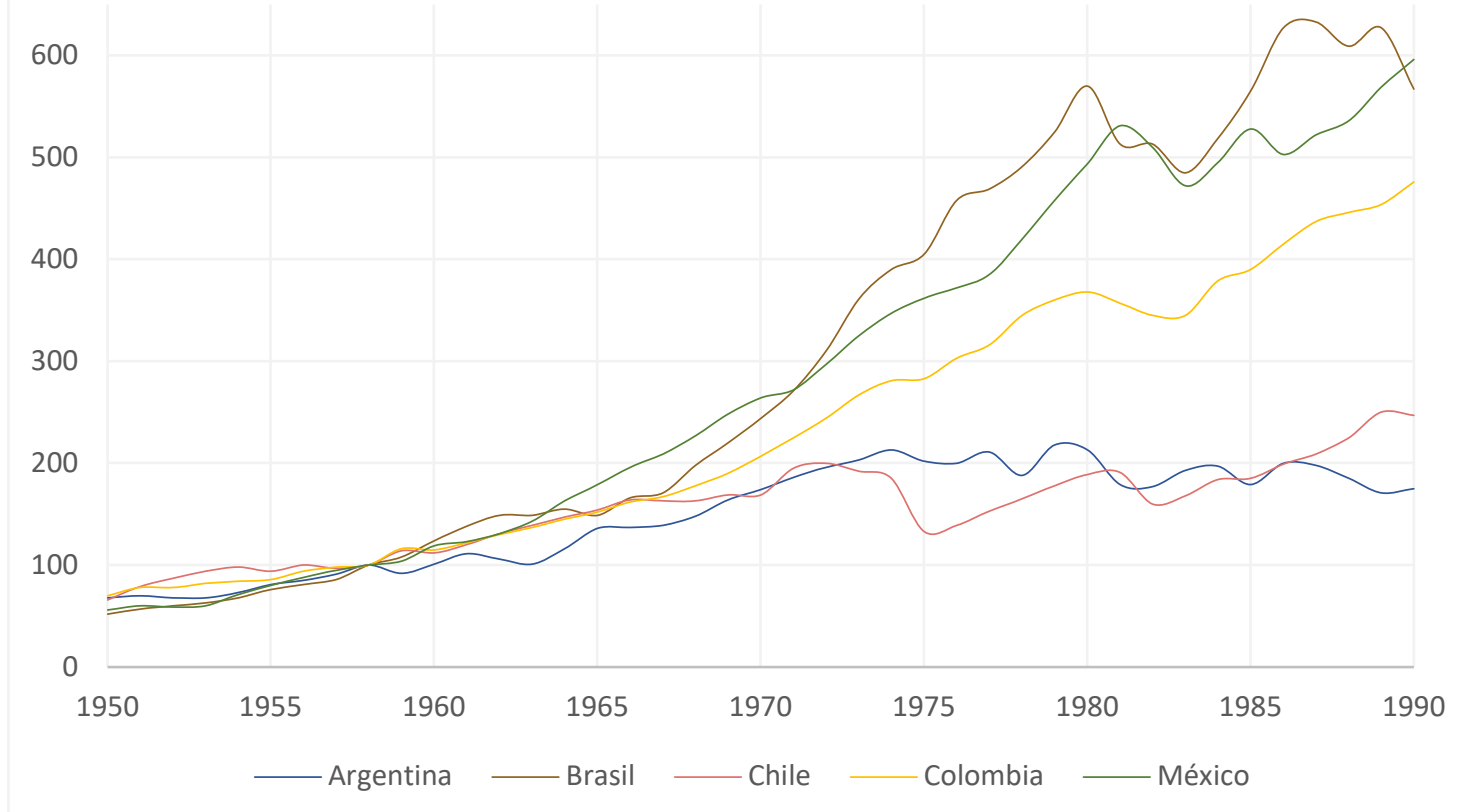

Fuente: elaboración propia a partir de Mitchell (1998, pp. 309-310).

Aunque algunos países de la región, AL6, experimentaron procesos de industrialización, la protección que se construyó alrededor de la industria local fue inconsistente, muchas veces se perfilaba en la protección de la balanza de pagos y no en la protección de las necesidades de la nueva industria. Además de los impuestos de importaciones, las políticas económicas confluyeron en múltiples tipos de cambio, cuotas de importaciones y licencias. América Latina se movilizaba en una dirección contraria a las naciones desarrolladas: después de largas negociaciones entre los países desarrollados, en el Acuerdo General sobre Aranceles Aduaneros y Comercio, GATT (General Agreement on Tariffs and Trade), los 


\section{Christian Paúl Naranjo Navas}

impuestos a las importaciones se redujeron considerablemente, mientras los aranceles en América Latina se mantuvieron altos, o aumentaba en el tiempo.

Después de las negociaciones, los países en vías de desarrollo recibieron presión para reducir los aranceles. En el caso de Brasil, no redujo sus niveles arancelarios, sino que, al mismo tiempo, para determinar los costos de las importaciones, introdujo un sistema de subasta de intercambio internacional (Bulmer-Thomas, 2007). Los países con más altas tasas nominales, durante la década de los sesenta, fueron Brasil, Argentina, Chile y Colombia. En el caso de México y Uruguay, los aranceles se mantuvieron bajos, sin embargo, los productos importados eran manejados con sistemas de cuotas.

Tabla 1. Tarifas nominales en porcentajes en AL6, 1960

\begin{tabular}{|c|c|c|c|c|c|c|}
\hline & $\begin{array}{c}\text { Bienes } \\
\text { de } \\
\text { consumo } \\
\text { de } \\
\text { durader } \\
\text { os }\end{array}$ & $\begin{array}{l}\text { Bienes } \\
\text { de } \\
\text { consumo } \\
\text { durader } \\
\text { os }\end{array}$ & $\begin{array}{c}\text { Bienes } \\
\text { manufacturad } \\
\text { os }\end{array}$ & $\begin{array}{l}\text { Materias } \\
\text { primas } \\
\text { industrial } \\
\text { es }\end{array}$ & $\begin{array}{l}\text { Biene } \\
\text { s de } \\
\text { capit } \\
\text { al }\end{array}$ & $\begin{array}{c}\text { Promedi } \\
\text { o }\end{array}$ \\
\hline Argentina & 176 & 266 & 95 & 55 & 98 & 131 \\
\hline Brasil & 260 & 328 & 80 & 106 & 84 & 168 \\
\hline Chile & 328 & 90 & 98 & 111 & 45 & 138 \\
\hline Colombia & 247 & 108 & 28 & 57 & 18 & 112 \\
\hline México & 114 & 147 & 28 & 38 & 14 & 61 \\
\hline Uruguay & 23 & 24 & 23 & 14 & 27 & 21 \\
\hline $\begin{array}{l}\text { Comunid } \\
\text { ad } \\
\text { Europea }\end{array}$ & 17 & 19 & 7 & 1 & 13 & 13 \\
\hline
\end{tabular}

Fuente: Bulmer-Thomas, 2007, p. 271.

A pesar del desarrollo industrial de algunas naciones latinoamericanas, el crecimiento del PIB de los países mencionados fue, a excepción de Brasil y México, en promedio, menor al 5\%. De 1950 a 1980, Argentina creció al 3,5\%, Chile al 3,2\%, Colombia al 5\%. Por otro lado, México creció al 6,5\% y Brasil al 7\%. Cuando se revisa el crecimiento per cápita, los promedios de crecimiento se reducen: Argentina en 1,8\%; Chile en 1,3\%; Colombia en 4,5\%, México en 3,4\% y Brasil en 4,3\% (Hofman, 2000, p. 31-32). Los datos muestran que la industrialización trajo consigo un escueto crecimiento económico en los casos de Argentina y Chile, y un mejor rendimiento en los casos de Colombia, México y Brasil.

Problemas del Modelo Cepalino 


\section{Sustitución de Importaciones e Industrialización. Desde el siglo XX hasta al Socialismo del Siglo XXI, caso Ecuador}

Además de los problemas de crecimiento económico, los países embarcados en la nueva tendencia de desarrollo enfrentaron problemas en la balanza de pagos y en la deuda pública. En la balanza de pagos porque la nueva industria generó nuevas necesidades de bienes de capital, lo que empujó el crecimiento de las importaciones. Por otro lado, el gasto público se convirtió en el principal propulsor de la economía, y se enfrentó con la disyuntiva de un constante aumento a partir de la generación de deuda.

\section{Balanza de pagos}

Durante la primera etapa de la ISI, el aumento de la protección al consumo interno trajo consigo un aumento en el déficit de divisas, dando como resultado constantes registros negativos en la balanza de pagos. Como se puede visualizar en la figura 2 , de 1950 a 1970, no existen registros positivos importantes; sin embargo, a partir de 1970 los registros negativos en la balanza de pagos aumentan de forma considerable. De acuerdo a Frieden (2006), este fenómeno es el resultado de un nuevo sector industrial que requería mayores importaciones de insumos para seguir creciendo. El crecimiento de la nueva industria creó una paradoja importante: el desarrollo de la industria recayó en el desequilibrio de la balanza de pagos.

Figura 2. Balanza de pagos en México, Argentina, Brasil y Colombia, 1950-1990, en millones de USD

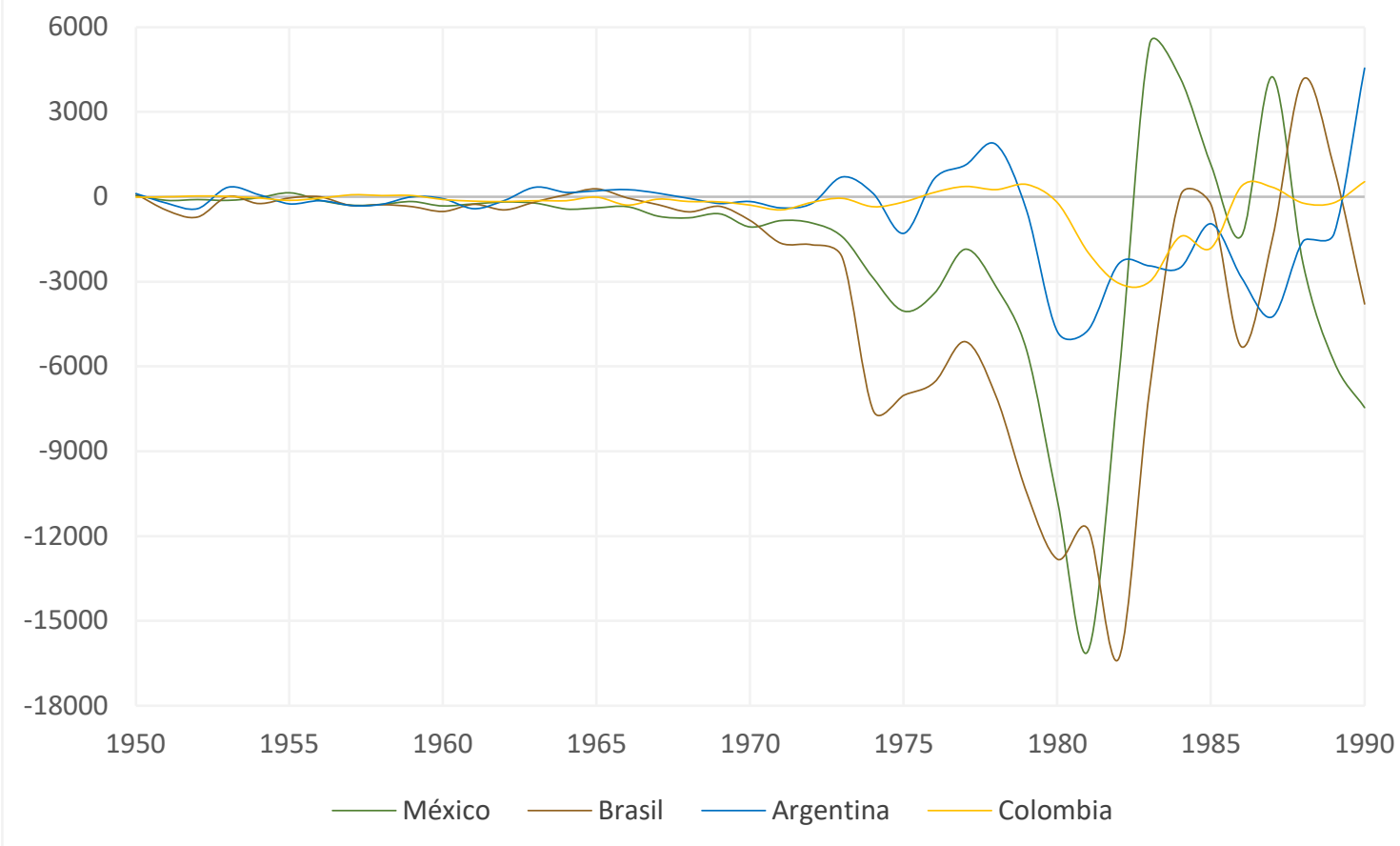

Fuente: elaboración propia a partir de Mitchell (1998, pp. 799-810).

En el caso colombiano, Vallejo (2003) menciona que el dinamismo de la industria presentó los primeros problemas de crecimiento al finalizar la década de los sesenta. Sin embargo, la industria que mantuvo un crecimiento constante fueron los 


\section{Christian Paúl Naranjo Navas}

productos elaborados, vehículos, productos químicos. Los problemas del modelo de desarrollo hacia adentro fue causado principalmente por el decrecimiento de la inversión productiva, la cual influyó sobre la demanda global. El modelo se agota y, en la década de los setenta, Colombia impulsa la diversificación de exportaciones para que el mercado externo a la manufactura de los productos industriales.

Para Aldo Ferrer (2010), el problema de Argentina recayó en la liberalización de las importaciones con una fuerte revaluación del tipo de cambio. En este sentido, Bonfanti (2015) señala que el desarrollo a largo plazo de Argentina fue imposible por el desmantelamiento de la industria, en concordancia con un creciente endeudamiento público y privado. Además, un elemento que también tuvo un impacto importante en el cambio de modelo fue la sobrevaluación de la moneda nacional porque fue considerada como un instrumento antinflacionario. A pesar de la liberación de las importaciones, tomando en cuenta las cifras de porcentajes de importaciones publicados por MOxLAD (2019), es evidente que las importaciones de bienes intermedios crecen de forma constante, de 30\% del total de importaciones en 1947, al 76\% en 1975.

En el caso de México, de acuerdo a los datos presentados por Godínez Montoya, Barrios, \& Figueroa (2015), la evolución de las cuentas corriente y de capital son diametralmente diferentes: por un lado, la cuenta corriente disminuye de forma constante desde 1970 hasta 1990, mientras que las cuentas de capital aumentan de forma sustancial, de menos de mil millones de dólares en 1970, a más de 20 mil millones de dólares en 1980. Estos datos muestran que, en el caso de México, las cuentas de capital desequilibraron la balanza de pagos. Además, la cuenta corriente registra déficits constantes generada en la balanza comercial, en la balanza de servicios factoriales y no factoriales, y por el exceso en las transferencias (Santiago, 2008).

Brasil muestra un desequilibrio profundo de la balanza de pagos entre 1970 y 1980, de hecho, los registros negativos son solo comparables con los de México (figura 2). Hasta 1970, el caso brasileño era ejemplificado como milagroso, esto fue posible a través del Plan SALTE (sanidad, alimentos, transporte y energía) en 1948, y el Plan Metas en 1956 (Márquez, 2010): los dos planes comprendieron políticas industriales y comerciales para promover el desarrollo económico de la nación. Los principales resultados adversos de esta política fueron la inflación y el desequilibrio de la balanza de pagos. De acuerdo a Márquez (2010), la decisión de promover las exportaciones y recomponer las importaciones, a favor de bienes intermedios y de capital, produjo altos índices inflacionarios que, en conjunto con la limitada oferta interna para satisfacer la demanda de bienes de consumo, condujo a que esta demanda interna sea cubierta por las importaciones.

\section{Deuda pública}




\section{Sustitución de Importaciones e Industrialización. Desde el siglo XX hasta al Socialismo del Siglo XXI, caso Ecuador}

Después de registrar problemas en la balanza de pagos, las posibilidades de endeudamiento llevaron a las naciones a períodos de endeudamiento, de forma que el dinero entrante pudiese dar respuesta a los ingentes déficits: los huecos fiscales fueron cubiertos por la deuda externa. El aumento de la deuda externa empujó a América Latina a la imprescindible reducción del gasto público, lo que provocó un estancamiento en el crecimiento económico. A partir de 1950, la creciente actividad de los gobiernos latinoamericanos en la economía trajo consigo una presión fiscal, la cual encontró nuevas fuentes de ingresos en la deuda externa. Sin embargo, el debate sobre el origen de la crisis de la deuda en la década de los ochenta sigue abierto. El modelo de sustitución de importaciones comenzó a genera fuertes críticas desde la ortodoxia económica como de la izquierda política (Love, 1994).

De acuerdo a Ocampo (2014), la ortodoxia económica criticaba el modelo por un poco disciplina macroeconómica y los problemas causados en el comercio exterior a causa de la protección arancelaria y paraarancelaria, mientras que desde la izquierda se criticaba la incapacidad de superar la dependencia externa. Ocampo también menciona que el tamaño del gobierno central se duplicó entre 1950 y 1982, del $12 \%$ al $22 \%$ del PIB. En principio, este crecimiento fue financiado por un constante aumento de los impuestos; sin embargo, a partir de la década de 1970, estos déficits se financiaron con deuda externa.

El fenómeno de la deuda externa no se visualiza hasta la etapa final del modelo de sustitución de importaciones: la ingente demanda de recursos trajo consigo la desbordante utilización de préstamos externos. Así, los problemas causantes del desequilibrio fiscal fueron solo visibles en la deuda externa a partir de la década de los setenta. En la tabla 2, y en la figura 3, se puede visualizar el aumento ingente de la deuda externa y de la deuda pública hasta 1990. El cambio de modelo, de la ISI al modelo neoliberal, cercano al modelo exportador antes de la crisis de la Gran depresión, aumentó el endeudamiento por un motivo importante: como una herramienta para salir de la crisis encausada por la ISI: la reducción abrupta de la deuda hubiese producido una comisión social que, a su vez, hubiese causado profundas inestabilidades políticas.

Tabla 2. Deuda pública y total en América Latina, miles de millones de USD

\begin{tabular}{lccc}
\hline & 1973 & 1977 & 1980 \\
\cline { 2 - 4 } Deuda pública & 27,0 & 71,6 & 123,6 \\
Deuda total & 42,8 & 104,2 & 205,4 \\
Participación de la deuda pública en el total & $63,1 \%$ & $68,7 \%$ & $60,2 \%$ \\
\hline
\end{tabular}

Fuente: elaboración propia a partir de Ffrench-Davis Muñoz, 1983, p. 287.

Figura 3. Deuda externa total en México, Argentina, Brasil y Colombia, 1970-1990, en millones corrientes de USD. 


\section{Christian Paúl Naranjo Navas}

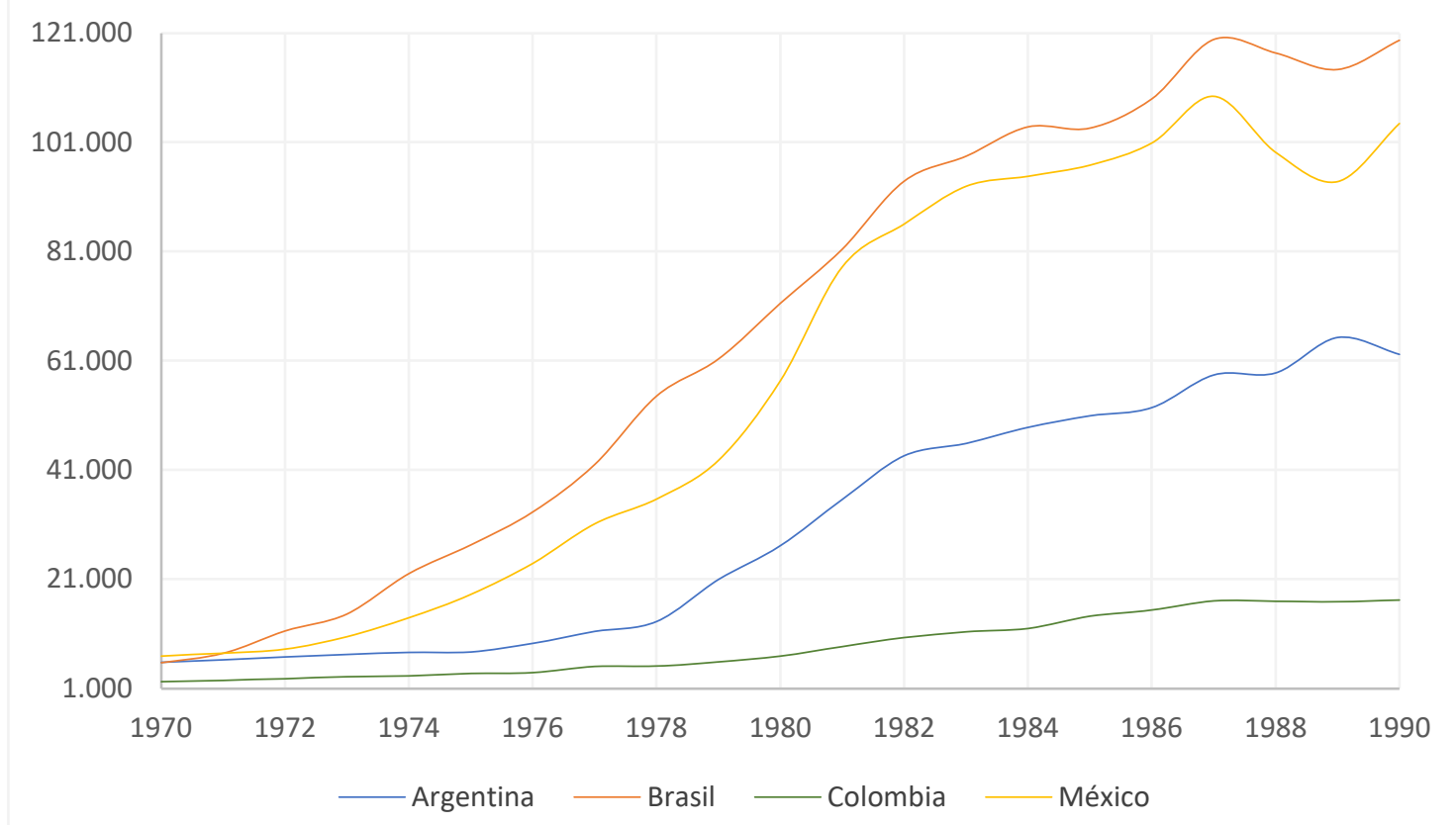

Fuente: elaboración propia a partir de MOxLAD (total external debt, 2019).

Como lo muestra Ocampo (2014), el balance fiscal de los países en América Latina es negativo desde 1950, con porcentajes inferiores al 2\% del Producto Interno Bruto. Sin embargo, estos porcentajes aumentan gradualmente de 1970 a 1982, de $1 \%$ a $5 \%$. Después, los registros negativos de los balances fiscales se reducen hasta 1991. La ingente necesidad de recursos provocó déficits constantes los cuales, en principio fueron cubiertos con el aumento impositivo y, luego, fueron cubiertos con deuda pública.

2. Ecuador durante la década de 2007-2017: Cambio de la matriz productiva y sustitución de importaciones

Rafael Correa empieza su mandato como presidente de la República de Ecuador en enero de 2007 a marzo de 2017. Su movimiento político, la "Revolución Ciudadana", se alineó rápidamente con las tendencias de izquierda latinoamericanos conocidas como parte del grupo del "Socialismo del Siglo XXI". Aunque Heinz Dieterich (2005) definía este movimiento como una democracia de mayorías participativas, Ramírez (2017) lo define como regímenes autoritarios, caudillistas y populistas. Este período de diez años de gobierno del nuevo socialismo en Ecuador se lo conoce como el "Correato", tiempo en el cual se hizo un énfasis continuo sobre la intencionalidad de retomar las ideas del período Cepalino, a decir, que Ecuador se enrumbe en un proceso propia de industrialización a través de la sustitución de importaciones. Este proceso se lo denominó como el cambio de la matriz productiva a través del direccionamiento de la planificación pública.

La planificación pública ha estado en manos de diferentes instituciones, como la Junta Nacional de Planificación y Coordinación Económica, JUNAPLA, de 1954 a 


\section{Sustitución de Importaciones e Industrialización. Desde el siglo XX hasta al Socialismo del Siglo XXI, caso Ecuador}

1978. En 1979, fue reemplazada por el Consejo Nacional de Desarrollo, CONADE. En 1998, la CONADE fue reemplazada por la Oficina de Planificación, ODEPLAN, y en 2004, se crea la Secretaría Nacional de Planificación y desarrollo, SENPLADES. Finalmente, en 2007, la SENPLADES se fusionó con el Consejo Nacional de Modernización del estado, CONAM, y con la Secretaría Nacional de los Objetivos de Desarrollo del Milenio, SODEM (Secretaría Nacional de Planificación y Desarrollo, 2019). Así, la SENPLADES se convirtió en el único organismo central de planificación nacional mediante la cual se intentó programar el cambio de la matriz productiva.

\section{Cambio de la matriz productiva}

A través de la planificación nacional, se construyó el Plan Nacional de Desarrollo 2007-2010, después de la generación de una nueva carta magna en 2008, se montó el Plan Nacional para el Buen Vivir 2009-2013, y, finalmente, el Plan Nacional para el Buen Vivir 2013-2017. De las planificaciones de desarrollo nacional, las dos últimas realizan un detalle del cambio de la matriz productiva. La planificación 2009-2013, el objetivo 11, sobre establecer un sistema económico social, solidario y sostenible, menciona la necesidad de recrear una economía endógena para el buen vivir, la inversión y las compras públicas orientadas a crear condiciones productivas, de forma que se pueda estimular el desarrollo de los sectores en desventaja (Consejo Nacional de Planificación, 2009).

La planificación de 2013-2017, expresa con claridad la transformación de la matriz productiva, el objetivo tres establece la transformación económico-productiva a partir del cambio de la matriz productiva. En este sentido, la planificación menciona la diversificación productiva basada en valor agregado, impulso a las exportaciones, y la sustitución de importaciones (Consejo Nacional de Planificación, 2013). Este plan menciona el objetivo de incrementar la participación industrial en el PIB, además del aumento de las exportaciones industrializadas.

Aunque el Plan Nacional para el Buen Vivir 2013-2017 mencione que el sector manufacturero de Ecuador creció a una tasa de 2,9 de 2002 a 2006, la información del Banco Central de Ecuador (2019) muestra que la tasa de crecimiento de la industria manufacturera, excluyendo la refinación de petróleo, en la misma temporalidad, fue de 5,6, mientras que de 2000 a $2006(2000=100)$, fue de 3,7. El único año de decrecimiento fue el 2000, con -6,8. Esto es entendible dado que en este año la economía de Ecuador tuvo una abrupta adaptación al cambio de moneda: el 9 de enero de 2000 se estableció el cambio de moneda, de sucres a dólares estadounidenses.

En el tiempo del régimen de Rafal Correa, como se puede visualizar en la figura 4, la tasa de crecimiento de la manufactura de 2007 a 2017 (2007=100) es de 3,0, mientras que la tasa de crecimiento del sector de la construcción fue de 4,7, de la agricultura de 0,3 , y del sector petrolero y minero de 0,3 . Estos datos muestran que el sector de mayor crecimiento fue el de la construcción, con un punto de inflexión 


\section{Christian Paúl Naranjo Navas}

en el 2011, año cuyo registro de crecimiento fue de 17,6. La construcción recibió un impulso importante a partir del crecimiento del gasto público. La tasa de crecimiento del gasto público, como se verá más adelante, se mantuvo positiva hasta el 2014, año en que los precios de las materias primas se derrumbaron de forma considerable.

Figura 4. Tasa de crecimiento de manufactura, petróleo y construcción en Ecuador, 2007-2017

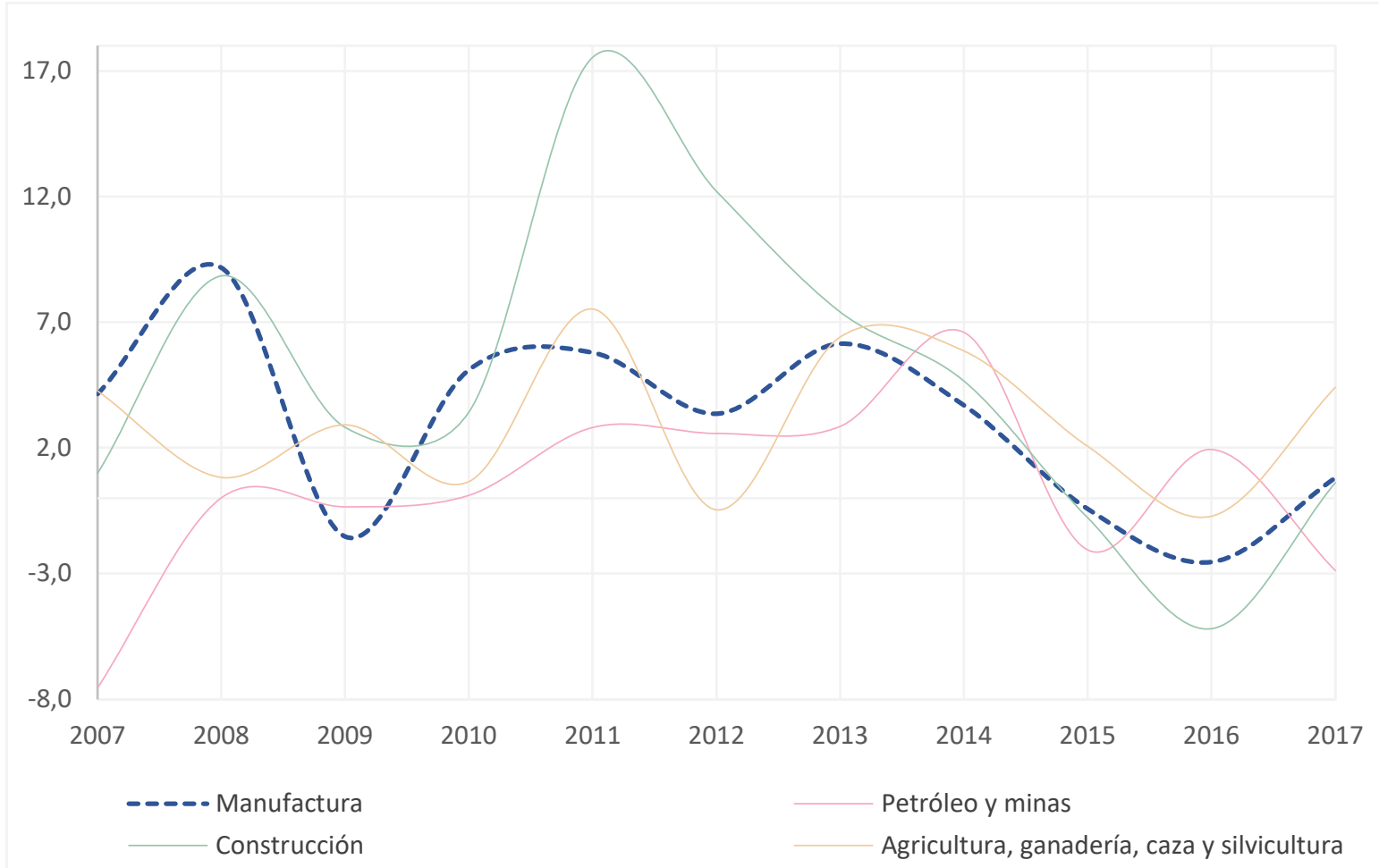

Fuente: elaboración propia a partir de Banco Central del Ecuador (2019)

Con los datos presentados, se puede concluir que el cambio de la matriz productiva en el sector manufacturero fue utilizado como muletilla del discurso político, pero, la discursiva no se convirtió en realidad. El sector manufacturero presenta tasas de crecimiento más altas en el período 2000-2006, que, durante la década de 2007 a 2017. El único sector con tasas altas de crecimiento fue el sector de la construcción. Sin embargo, a partir del 2014, todos los sectores de la economía registraron tasas mínimas o negativas de crecimiento. Los precios de petróleo WTI cayeron de 111 USD en el 2014, a 36 USD en febrero de 2016 (Macrotrends, 2019), lo que ejemplifica que la economía en su conjunto se encontraba altamente dependiente del sector de materias primas.

Problemas del modelo económico durante el gobierno de Rafael Correa 


\section{Sustitución de Importaciones e Industrialización. Desde el siglo XX hasta al Socialismo del Siglo XXI, caso Ecuador}

El modelo económico del régimen recae en problemas similares a los problemas presentados durante el período cepalino, a decir: problemas en la balanza de pagos, y en el aumento del gasto de gobierno, el cual devino en un eventual aumento en la deuda pública. Estos elementos comunes asemejan los casos estudiados con el período de diez años del socialismo de siglo xxi, sin embargo, existe un elemento único, el sistema de dolarización aplicado por el gobierno ecuatoriano en el 2000. La dolarización se construyó como un modelo monetario que restringió el aumento del circulante. Lo contrario, a decir, sin restricciones al aumento del circulante, hubiese provocado un mayor gasto público y crecientes tasas inflacionarias. La rigidez del aumento de la oferta monetaria restringió las tasas inflacionarias y la devaluación inminente de la moneda nacional.

\section{Importaciones}

El cambio de la matriz productiva hubiese llevado a un aumento de la producción manufacturera; sin embargo, como se visualiza en la figura 4, el sector manufacturero creció de forma escueta, a un ritmo similar a la agricultura o el sector minero. Un eventual cambio de la matriz productiva también hubiese llevado al crecimiento de las tasas de importación de bienes de capital, una consecuencia esperada tomando en consideración los ejemplos estudiados del modelo cepalino de los 50s y 60s. No obstante, la figura 5 muestra que, por el contrario, las tasas de crecimiento de las importaciones de bienes de capital disminuyeron del 2011 al 2016, a una tasa promedio de -3,1\%. La evolución de las importaciones coincide con la creación y aumento del impuesto a la salida de divisas, ISD. El ISD de 0,5\% fue creado el 2008, después, en el 2010 aumentó al 2\%, y en el 2011 al 5\%. Este impuesto recaudó en promedio 300 millones de dólares anuales (El Universo, 2011). Sin embargo, no se puede argumentar con certeza que las importaciones se redujeron a causa del aumento de la presión fiscal, ya que, como se verá en la próxima sección, aunque la presión fiscal aumenta en 10 años, ésta se ubica en la media de la región latinoamericana.

Figura 5. Tasa de crecimiento de importaciones de bienes de consumo, materias primas y bienes de capital, 2007-2017 


\section{Christian Paúl Naranjo Navas}

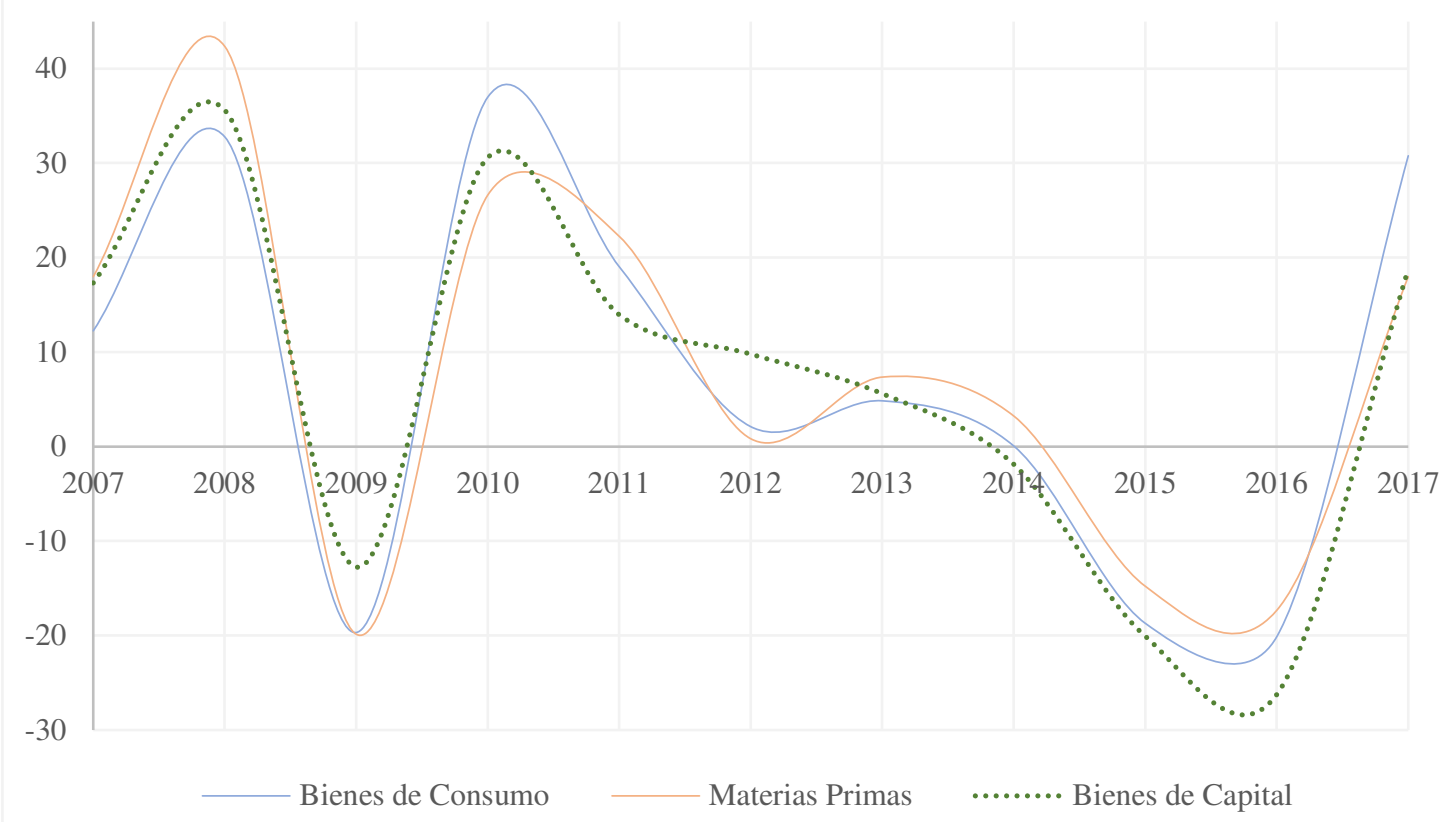

Fuente: elaboración propia a partir de Banco Central del Ecuador (2020)

\section{Balanza de pagos}

El Plan Nacional de Desarrollo (Consejo Nacional de Planificación, 2013) menciona la profundización de la transformación del sector industrial a través de la sustitución de importaciones, con la idea de obtener una balanza comercial no petrolera en niveles de equilibrio. Estas medidas tenían el objetivo de contribuir con las exportaciones de servicio y productos con valor agregado. El arancel aplicado de media ponderada sube de 4,2 en el 2011 a 7,0 en el 2017 (Banco Mundial, 2019). Aunque las tasas arancelarias suben de forma importante, las tasas arancelarias en la década de los noventa fueron más altas, en promedio, de 1993 a 2000, el arancel fue de 10,42. De esta forma, es evidente que los niveles de proteccionismo aumentaron en la década de 2007 a 2018, sin embargo, los niveles fueron más altos en la década de los noventa.

Por otro lado, a partir de 2007, la balanza de pagos, así como la balanza comercial (figura 6), registran déficits hasta el 2016, lo que propone que tanto el sector importador como el sector exportador decrecieron de forma importante. En este caso, el desequilibrio no es causado por una industria creciente que tiene la necesidad de importar bienes de capital o bienes intermedios, sino que es causado por la reducción de los niveles de exportaciones e importaciones. Aunque no se puede argumentar con certeza que la reducción del comercio exterior fue causada por el aumento de impuestos, es claro que la presión fiscal equivalente, con relación al Producto Interno Bruto, creció considerablemente del 14\% en el 2006 a 22\% en el 2017 (Banco Interamericano de Desarrollo, 2020). El promedio de la región se encontró en el 24\% en el 2017, siendo Cuba (42\%), Uruguay (36\%) y Argentina (33\%) los países de mayor presión fiscal equivalente; y Guatemala (12\%), Paraguay 


\section{Sustitución de Importaciones e Industrialización. Desde el siglo XX hasta al Socialismo del Siglo XXI, caso Ecuador}

(15\%) y República Dominicana (16\%) los de menor presión. Requiere de otra discusión argumentar si estos niveles jugaron en contra de Ecuador en el período estudiado.

Figura 6. Balanza de pagos y balanza comercial en Ecuador, millones de USD, 20072017

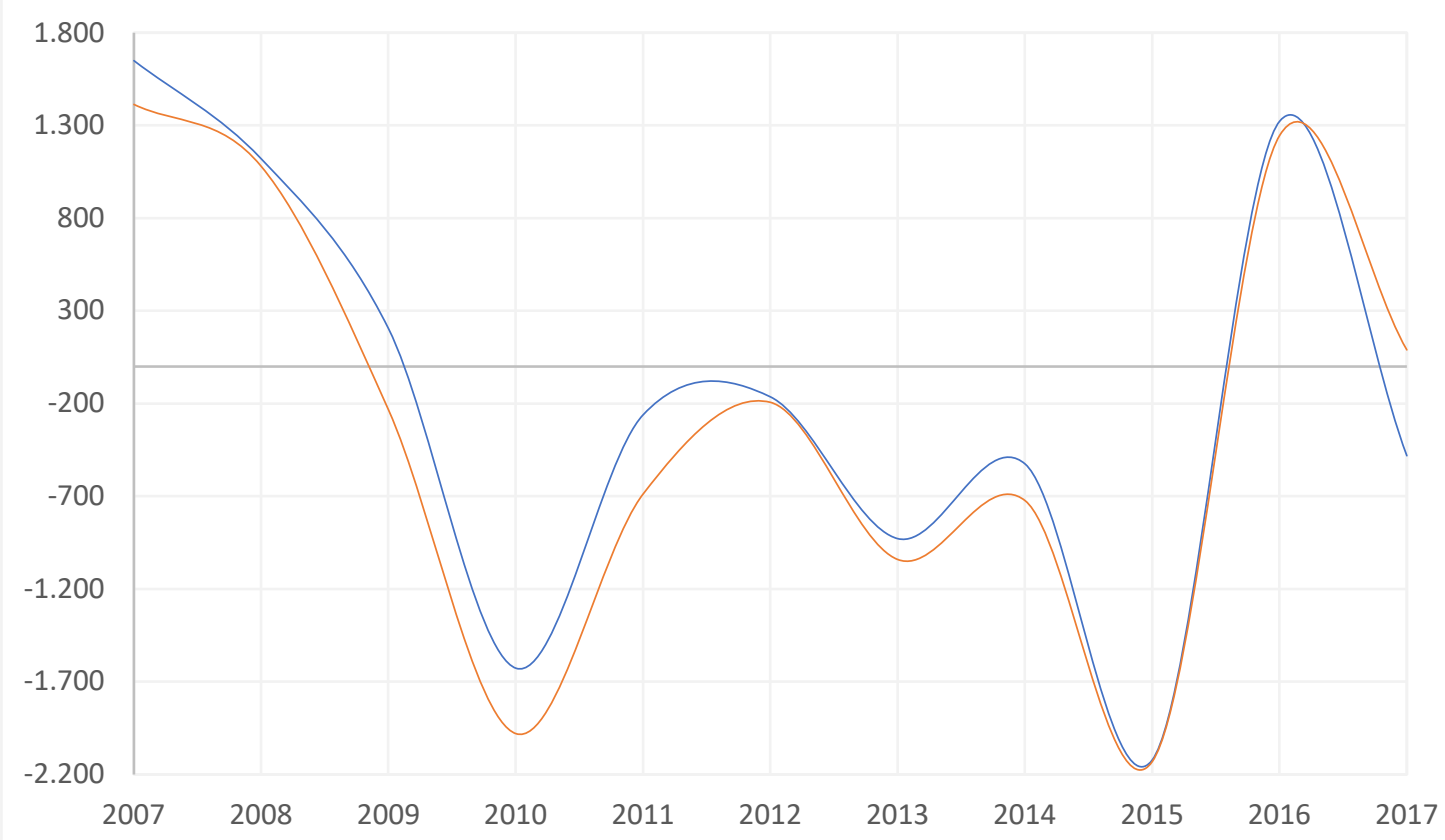

Fuente: elaboración propia a partir de Banco Central del Ecuador (2018)

El impacto causado por el desequilibrio de la balanza de pagos hubiese causado, con moneda nacional, un aumento de la emisión monetaria lo que, a su vez, hubiese causado niveles inflacionarios preocupantes. No obstante, en el caso ecuatoriano, el desequilibrio de la balanza de pagos puso en peligro el sistema monetario basado en el dólar estadunidense. La sostenibilidad del sistema monetario depende de los flujos monetarios externos, como las exportaciones, las remesas, la inversión extranjera y la deuda pública (Naranjo Navas, 2018). De esta forma, el desequilibrio de la balanza de pagos puso en riesgo la estabilidad del sistema monetario en Ecuador.

\section{Crecimiento y gasto de gobierno}

Bose (2007), después de examinar los efectos en el crecimiento del gasto gubernamental en un conjunto de 30 países durante los años 70 y 80, llega a dos aproximaciones. Primero, menciona que la participación del gasto de capital del gobierno en el PIB se correlaciona de manera positiva y significativa con el crecimiento económico, mientras que el gasto corriente es insignificante en el crecimiento del PIB. Segundo, la inversión del gobierno en educación y los gastos 


\section{Christian Paúl Naranjo Navas}

totales en educación son los únicos desembolsos que se asocian significativamente con el crecimiento. En el mismo sentido, Lupu, Petrisor, Bercu y Tofa (2018) concluyen que los gastos en educación y salud tienen un impacto positivo en la economía, mientras que los gastos en defensa, asuntos económicos, servicios públicos generales y bienestar social tienen un impacto negativo.

El gasto total ecuatoriano en educación, en relación al PIB, aumenta de 4,34 a 5,26, de 2009 a 2015 (United Nations Edducational, Scientific and Cultural Organization, 2019). A partir de entonces, la relación disminuye de forma constante hasta 2017. Por otro lado, el gasto en salud, con relación al PIB, aumenta de 5,8 a 8,4, de 2007 a 2012 (World Bank, 2019). A partir de entonces, el gasto en salud se estanca hasta el 2017. Aunque la correlación entre el gasto total de gobierno y el crecimiento del PIB no es alta $\left(R^{2}=0,451\right)$, como se puede visualizar en la figura 7 , el crecimiento del gasto total del gobierno coincide en varios años con el crecimiento del PIB hasta el 2012. A partir de este año, el gasto de gobierno y el crecimiento del PIB disminuyen de forma constante. La disminución del gasto público, generado a partir de la disminución de los precios de las materias primas, llevó al gobierno de Ecuador a intentar sostener el gasto total a través de la deuda pública.

Figura 7. Tasa de crecimiento de gasto de gobierno y PIB en Ecuador, 2007-2017,

$$
2007=100
$$

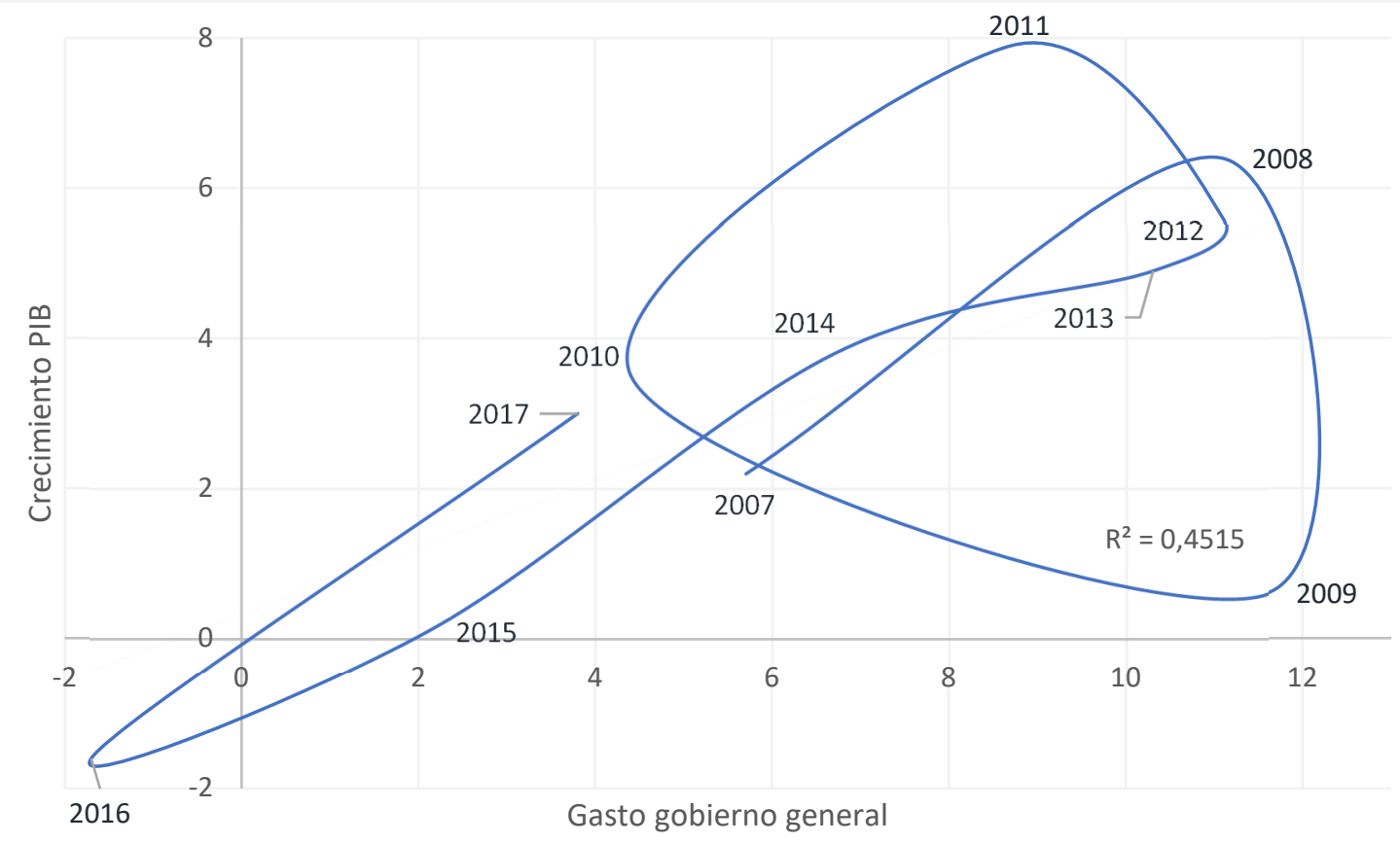

Fuente: elaboración propia a partir de Banco Central del Ecuador (2019)

La deuda pública (figura 8) se convirtió en un problema importante del modelo económico del gobierno del socialismo del siglo xxi. Aunque el aumento del gasto en salud y educación coincide con el crecimiento del PIB, el aumento del gasto público, a partir de la disminución de los precios de las materias primas, estaba siendo financiado por la deuda pública. Para intentar dar un tipo de solución los problemas 


\section{Sustitución de Importaciones e Industrialización. Desde el siglo XX hasta al Socialismo del Siglo XXI, caso Ecuador}

emergidos por la disminución de los precios del petróleo, el gobierno ecuatoriano encontró niveles inesperados de deuda pública, la cual fue utilizada como una burbuja de protección que esperaba la recuperación de los precios internacionales de las materias primas.

En el 2008, se crea la Comisión de Auditoría Integral del Crédito Público. La comisión presentó informes en los cuales se cuestionaba la legalidad y legitimidad de ciertas secciones de la deuda externa. Con este informe, el gobierno genera un plan muy controvertido: después del anuncia de la suspensión de pago de los bonos Global 2012 y 2030, se recompra los bonos al 25\% del valor nominal, generando un ahorro de alrededor de 2 mil millones de dólares. Esta maniobra generó incertidumbre en los mercados internacionales, esto fue visible en el índice de riesgo país, el cual se dispara de 582 puntos en junio de 2008, a 5000 puntos en diciembre del mismo año (Banco Central del Ecuador, 2009). El riesgo se mantuvo alto durante el primer semestre de 2009, entre 4000 y 1000 puntos. A partir de 2009, la deuda pública aumenta progresivamente hasta sobrepasar el límite legalmente establecido por la Asamblea Nacional

A partir de 2016, la deuda pública total sobrepasa la barrera legal estipulada en el Código Orgánico de Planificación y Finanzas Publicas (Asamblea Nacional, 2010). Este fenómeno ocurre a pesar de que el artículo 124 del código estableció que el monto total de la deuda pública, realizada por el conjunto de las entidades y organismos del sector público, en ningún caso podrá sobrepasar el cuarenta por ciento (40\%) del PIB. El mismo artículo propuso una salida al límite de la deuda pública, la aprobación de la Asamblea Nacional del sobreendeudamiento a través de una mayoría absoluta, es decir con las tres cuartas parte del número total de asambleítas. Sin embargo, durante los últimos años de la década estudiada, la Asamblea Nacional no recibió ningún pedido de la Presidencia de la República como aviso y permiso para el sobreendeudamiento, y tampoco hubo ningún reclamo formal de parte de la Asamblea Nacional.

Figura 8. Deuda pública como porcentaje de PIB y tasa de crecimiento de PIB en Ecuador, 2007-2017, 2007 $=100$ 


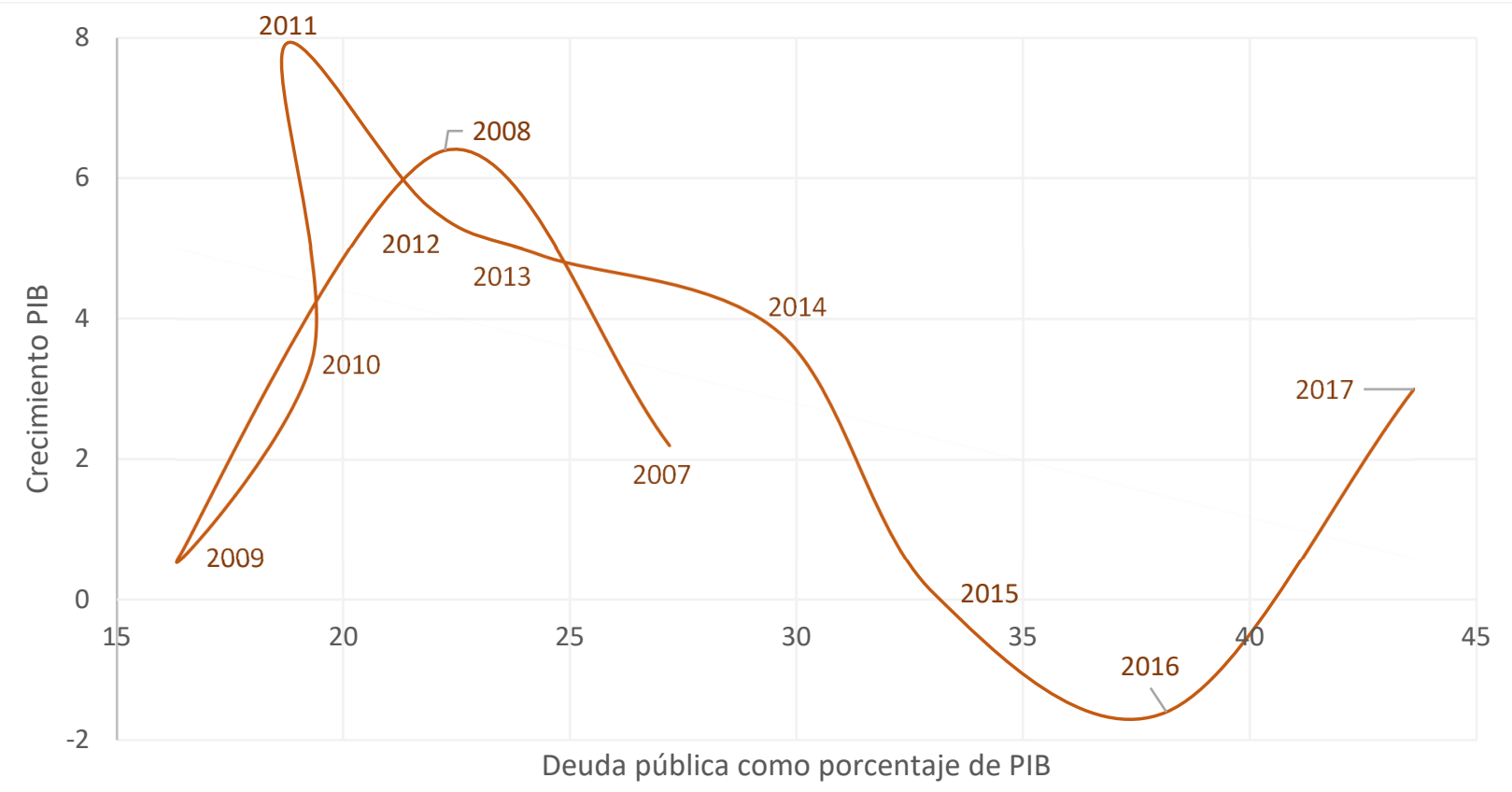

Fuente: elaboración propia a partir de Banco Central del Ecuador (2019).

Después de consolidar la deuda pública, el gobierno ecuatoriano pudo haber encontrado una solución legal a través de la solicitud de sobreendeudamiento; sin embargo, la decisión fue de no declarar ciertas obligaciones contraídas como parte de la deuda pública. Entre los rubros que no se consideraron se encontraron: la deuda contraída con el Fondo Monetario Internacional; la deuda con el Banco Central del Ecuador y el Ministerio de Finanzas; la venta anticipada de petróleo; la deuda al sistema de seguridad social (Naranjo Navas, 2018). En total la deuda no declarada sumó alrededor de 10 mil millones de dólares, lo que significó 15 puntos extras en la relación deuda externa/PIB. Desde el 2018, las cifras oficiales del Banco Central del Ecuador, y del Ministerio de Finanzas, registran estos rubros como parte de la deuda pública.

\section{Oferta Monetaria y dolarización}

El cambio de la matriz productiva, a través de la sustitución de importaciones, se encontró con una particularidad, la moneda nacional era el dólar estadounidense, lo que restringió los procesos devaluatorios como parte de las políticas monetarias, y presentaría un problema real: el desbalance de la balanza de pagos pondría el riesgo el sistema monetario. Durante la década estudiada, la dolarización se convierte en un frágil delineamiento de prosperidad si no se atiende su principal insumo de vitalidad, el flujo de dinero que proviene del exterior. Por un lado, la restricción monetaria puso límites a las fluctuaciones inflacionarias; por otro lado, el único flujo de dinero visible, durante la década estudiada, fue la deuda pública. 


\section{Sustitución de Importaciones e Industrialización. Desde el siglo XX hasta al Socialismo del Siglo XXI, caso Ecuador}

Por un lado, la inflación se mantuvo baja desde el 2002, con un promedio anual de 5\% (The Global Economy, 2019); por otro lado, el sistema monetario de la dolarización encontró dos riesgos eminentes: primero, el ingreso de nuevos dólares dependía de la balanza comercial, la deuda pública, las remesas y la inversión extranjera (Naranjo Navas, 2018); segundo, influjo de dinero más utilizado fue la deuda pública. Tomando en cuenta este panorama, como hemos visto, los principales problemas del modelo económico trajeron consigo problemas en los registros negativos de la balanza de pagos que, combinados con una creciente deuda pública, ponía en riesgo el sistema monetario a mediano plazo. Con se puede observar en la figura 9, con relación a las remesas, de 2007 a 2017, el promedio de crecimiento es negativo hasta el 2015. A partir de entonces, la tasa de crecimiento es insignificante. Por otro lado, la inversión extranjera presenta altas tasas de crecimiento hasta el 2011, especialmente por los ingentes rubros provenientes del sector de la construcción (BCE-SIGADE, 2018).

Figura 9. Tasas de crecimiento de IED y remesas, 2007-2017

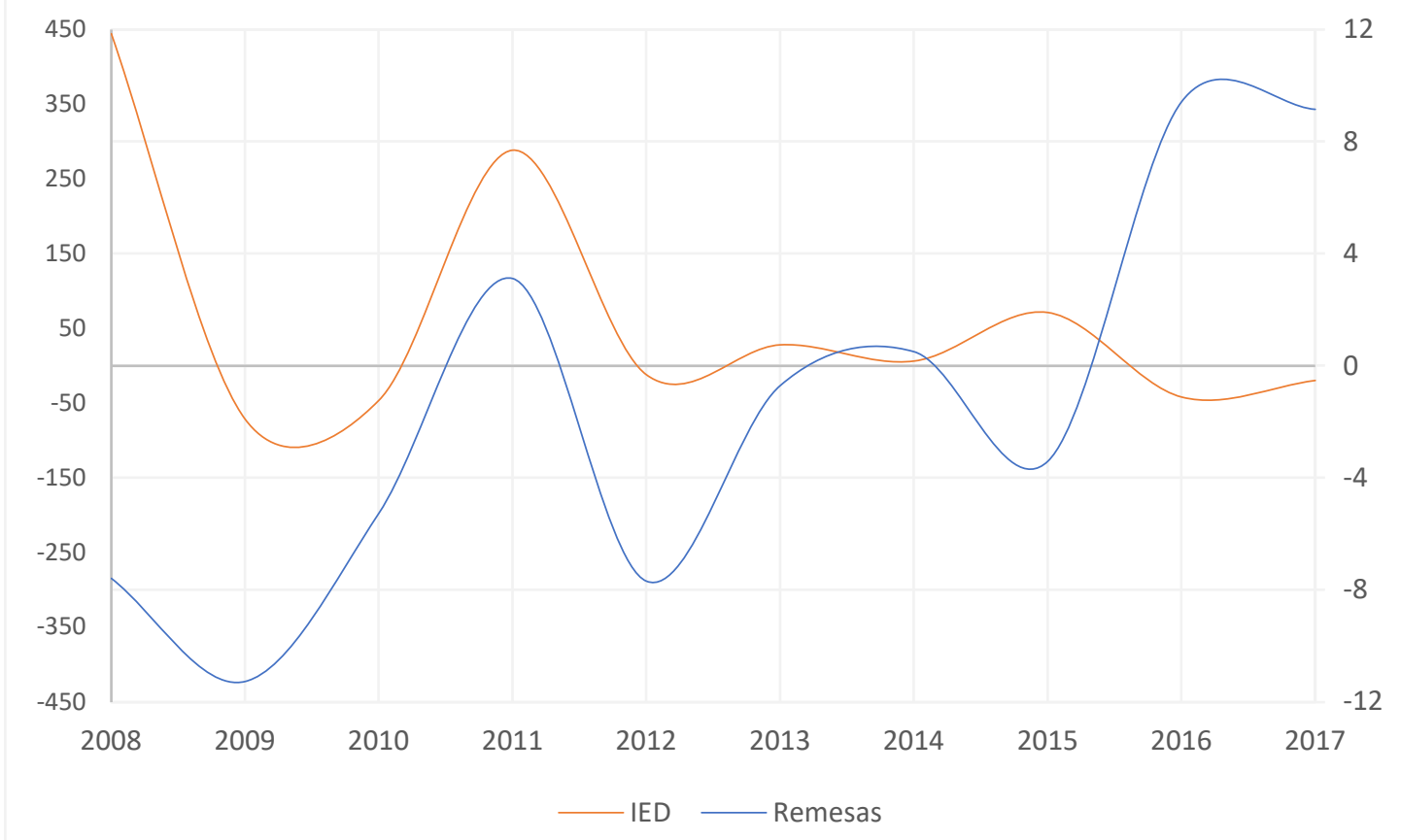

Fuente: elaboración propia a partir de Banco Central del Ecuador (2018), para remesas; y, BCE-SIGADE (2018), para inversión extranjera directa.

Nota: remesas se encuentran graficadas en el eje secundario.

La vitalidad del sistema de dolarización depende de la oferta monetaria (figura 10), y la oferta monetaria depende del ingreso de dólares. De esta forma, la vitalidad del sistema monetario depende de la atracción de las inversiones extranjeras, las remesas, el comercio externo, y de la deuda externa. De estos factores, las políticas económicas se caracterizaron por el aumento de la deuda pública, dejando de lado las otras fuentes monetarias. La inversión extranjera reduce sus tasas de 


\section{Christian Paúl Naranjo Navas}

crecimiento anual de forma dramática, los porcentajes de crecimiento de las remesas son muy pequeños, mientras que la balanza comercial presenta registros negativos en la mayor parte de la década de 2007 a 2017. El sistema monetario fue sostenido por la deuda pública, la cual se triplicó de 2009 a 2017.

Figura 10. Tasas de crecimiento de M2, 2007-2017

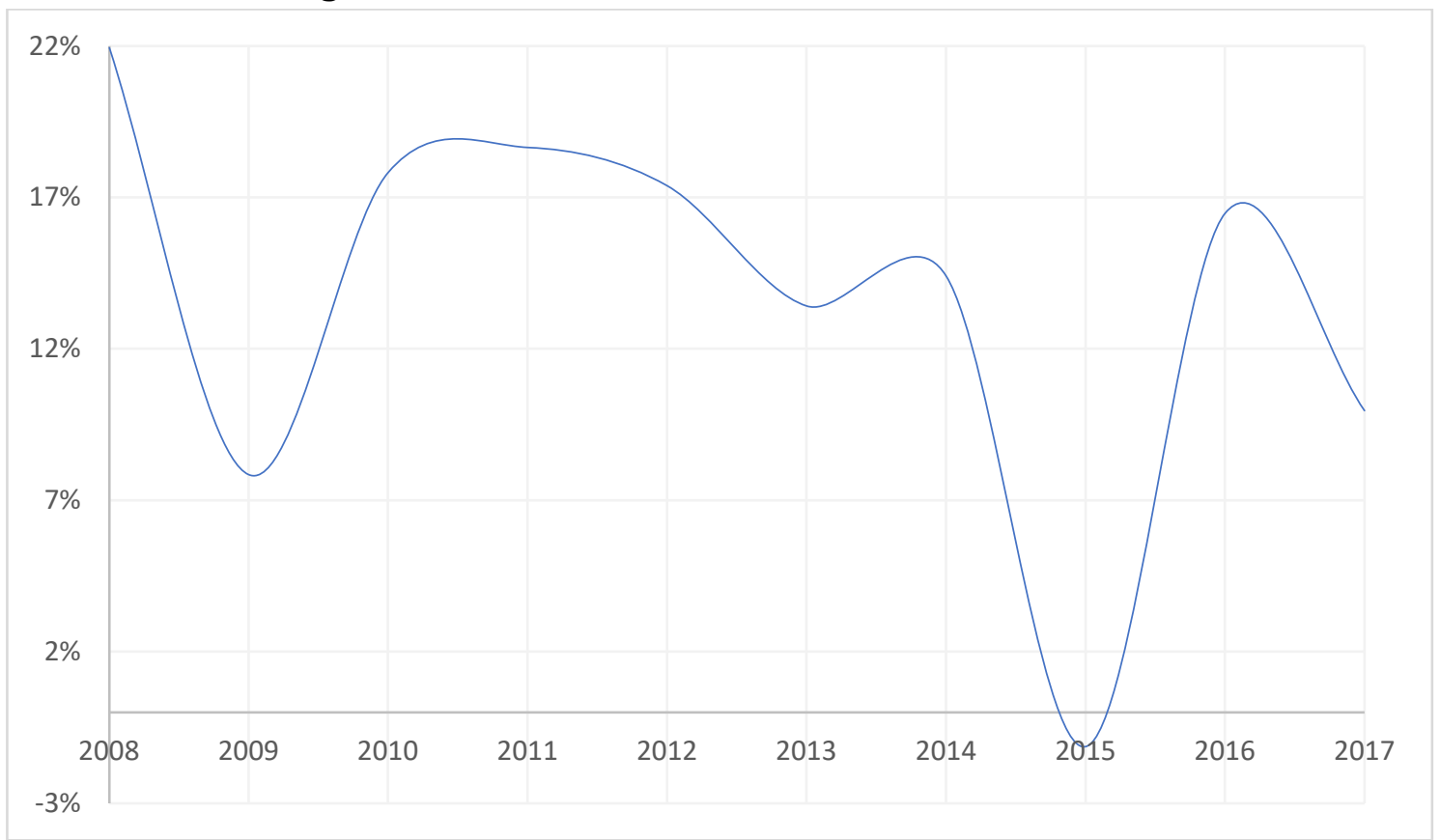

Fuente: elaboración propia a partir de Banco Central del Ecuador (2019).

La evaluación del sistema monetario es visible en la evolución de la oferta monetaria. La tasa de crecimiento del M2 se encuentra entre 7 y 18 puntos hasta el 2014. Como se observa en la figura 8, la tasa de crecimiento cae abruptamente en el 2015, y en el 2017. En el 2016, el último año de gobierno, el cual buscaba la elección a la presidencia de un amigo cercano del régimen, Lenin Moreno, se empuja la actividad pública: el gasto público se activa a través de la deuda pública, en el 2016, el gasto público y la deuda pública aumentan en 5 puntos. Así se puede entender que la tasa de crecimiento de la oferta monetaria se recupera en el 2016, y luego vuelve a bajar.

\section{Conclusiones}

La influencia del modelo cepalino, fundamentado en la Industrialización y Sustitución de Importaciones, ha influenciado la región por más de media centuria. El modelo impactó de forma profunda América Latina durante las décadas de los cincuenta y sesenta, y tuvo un impacto inimaginado en el movimiento del Socialismo del Siglo XXI. En ambos casos, la fortalece del crecimiento económico y de la industrialización estaba en el papel del gasto público. El papel del gasto público se convierte en una de las piedras angulares del desarrollo regional, sin embargo, el 


\section{Sustitución de Importaciones e Industrialización. Desde el siglo XX hasta al Socialismo del Siglo XXI, caso Ecuador}

modelo trajo varios problemas: la creciente inestabilidad en la balanza comercial, tomando en cuenta que las nuevas industrias necesitaban de crecientes insumos como materia prima o maquinaria; $y$, la creciente deuda requerida para los programas de infraestructura que necesitaban los nuevos planes de industrialización de las naciones latinoamericanas.

El desarrollo industrial de algunas naciones latinoamericanas fue muy evidente, sin embargo, el crecimiento del PIB de países como Brasil, México, Chile, Argentina y Colombia promediaba $4 \%$ anual. Cuando se revisa el crecimiento per cápita, los promedios de crecimiento se reducen: Argentina en 1,8\%; Chile en 1,3\%; Colombia en 4,5\%, México en 3,4\% y Brasil en 4,3\%. Además, el balance fiscal de los países en América Latina es negativo desde 1950. La ingente necesidad de recursos provocó déficits constantes los cuales, en principio fueron cubiertos con el aumento impositivo y, luego, fueron cubiertos con deuda pública. Por otro lado, el fenómeno de la deuda externa no se visualiza hasta la etapa final del modelo de sustitución de importaciones. La ingente demanda de recursos trajo consigo la desbordante utilización de préstamos externos. Los problemas causantes del desequilibrio fiscal fueron solo visibles en la deuda externa a partir de la década de los setenta.

Un modelo similar a la Industrialización y Sustitución de Importaciones fue instaurado por el gobierno de Rafael Correa, a través del movimiento político Revolución Ciudadana. El gobierno de Correa estableció un proceso similar a la ISI a través de un incremento en el gasto público y a través del plan denominado "cambio de la matriz productiva". Los resultados del régimen se asemejan a los resultados de la ISI, a decir, un desequilibrio de la balanza de pagos; y, una creciente deuda pública. Sin embargo, el desequilibrio de la balanza de pagos no fue causada por el creciente número de industrias que requerían insumos, sino, por la disminución abrupta del comercio externo: tanto las importaciones como las exportaciones registraron una disminución importante hasta el 2016.

A partir de 2016, la deuda pública total sobrepasa la barrera legal estipulada. La forma de sobrepasar las limitaciones legales fue el ocultamiento de la deuda a través de maniobras contables. Entre los rubros que no se consideraron se encontraron: la deuda contraída con el Fondo Monetario Internacional; la deuda con el Banco Central del Ecuador y el Ministerio de Finanzas; la venta anticipada de petróleo; la deuda el sistema de seguridad social. En total la deuda no declarada sumaba alrededor de 10 mil millones de dólares, lo que significaba 15 puntos extras en la relación deuda externa/PIB, es decir, para el 2017, la relación real deuda pública/PIB era del $43 \%$, tres puntos por encima del límite legal. Este porcentaje subirá 8 puntos más durante el 2018.

En el caso ecuatoriano, se puede argumentar que el gasto gubernamental del gobierno ecuatoriano entre 2007 y 2017 sirvió para la generación de mega obras (Senplades, 2017) como carreteras (268 tramos de carreteras), hidroeléctricas (8 centrales), la construcción de nuevos hospitales (21 hospitales y 21 centros de salud) o en educación (4 nuevas universidades). Sin embargo, después de pocos años, la revisión minuciosa muestra que la mayoría de estas mega obras recayeron 


\section{Christian Paúl Naranjo Navas}

en ingentes sobreprecios, lo que llevó al juicio del caso conocido como "sobornos 2012-2016" (Fiscalia General del Estado, 2020), en el cual se sentenciaron a 8 años de reclusión a 18 personas, incluyendo al expresidente Rafael Correa y al ex vicepresidente Jorge Glas.

Aunque los modelos se asemejan de forma importante, el artículo muestra que existen dos elementos que son exclusivos del tiempo de 2007 a 2017. Primero, Ecuador no cuenta con una moneda propia, sino que, desde enero de 2000, su moneda oficial es el dólar estadounidense. Segundo, la masa monetaria depende directamente del ingreso de dólares a la economía, a decir, la vitalidad del sistema de dolarización depende de la oferta monetaria, y la oferta monetaria depende del ingreso de dólares. Estos dos elementos, relacionados estrechamente, hacen del caso ecuatoriano un caso de estudio diferente a los otros casos del socialismo del siglo XXI. El artículo concluye que el modelo cepalino y el modelo económico ecuatoriano produjeron resultados similares, con dos variantes: primero, en el caso ecuatoriano no se registra problemas con las fluctuaciones inflacionarias; segundo, el sistema monetario de Ecuador depende del flujo de dinero del exterior.

A pesar de los problemas causados por los modelos de industrialización a partir de la sustitución de importaciones, Colin (2019) propone dos preguntas interesantes: ¿podría la expansión industrial posterior a la década de 1970 de países como Brasil y México ser posible sin la plataforma de fabricación establecida durante la era clásica de la industrialización de sustitución de importaciones entre 1945 y 1972/3? ¿Se podrían haber logrado ganancias de productividad sin una acción estatal comprensiva? Aunque sus respuestas apuntan a la improbabilidad de los escenarios propuestos, la argumentación queda relegada a una hipótesis imposible de ser respondida. De la misma forma, el lector podría preguntarse ¿pudo haber sido posible la expansión industrial de países como Brasil o México a través de la inversión privada, dejando de lado la intervención estatal? Aunque la respuesta pueda apuntar a una alta probabilidad, la hipótesis es imposible de ser respondida porque los escenarios alternos son solo eso, alternos. En cualquier caso, las consecuencias del modelo de industrialización por sustitución de importaciones fueron claros: el desequilibrio de la balanza de pagos, una creciente deuda pública.

\section{Referencias}

Asamblea Nacional. (2010). Código Orgánico de Planificación y finanzas Públicas. Quito.

Banco Central del Ecuador. (10 de junio de 2009). Riesgo país. Obtenido de https://contenido.bce.fin.ec/resumen ticker.php?ticker value=riesgo pais

Banco Central del Ecuador. (2018). Balanza de pagos, balanza comercial. Quito, Ecuador. Obtenido

de https://contenido.bce.fin.ec/home1/estadisticas/bolmensual/IEMensual.jsp 


\section{Sustitución de Importaciones e Industrialización. Desde el siglo XX hasta al Socialismo del Siglo XXI, caso Ecuador}

Banco Central del Ecuador. (2018). Remesas base de datos. Obtenido de https://contenido.bce.fin.ec/frame.php?CNT=ARB0000985

Banco Central del Ecuador. (2019). Producto interno bruto por industria. Quito. Obtenido de https://contenido.bce.fin.ec/home1/estadisticas/bolmensual/IEMensual.jsp

Banco Central del Ecuador. (2019). Gasto de gobierno. Quito. Obtenido de https://contenido.bce.fin.ec/home1/estadisticas/bolmensual/IEMensual.jsp

Banco Central del Ecuador. (2020). Importaciones por uso o destino económico. Recuperado el 13 de junio de 2020, de Importaciones por uso o destino económico (Tasas de variación): https://contenido.bce.fin.ec/documentos/PublicacionesNotas/Catalogo/IEMensua l/m1955/IEM-316a.xls

Banco Interamericano de Desarrollo. (2020). Presión Fiscal Equivalente (PFE) en América Latina $y$ el Caribe. BID_CIAT. Obtenido de https://ciatorg.sharepoint.com/:x:/s/cds/EZy4zl2AZoBLl8kzhItUAMBoGJ03QXenXwMZS gl]85mw?e=9KLUQe

Banco Mundial. (2019). Tasa arancelaria, aplicada, promedio ponderado, todos los $\begin{array}{lllll}\text { productos } & \text { (\%). } & \text { Recuperado de }\end{array}$ https://datos.bancomundial.org/indicador/TM.TAX.MRCH.WM.AR.ZS?locations=E $\underline{\mathrm{C}}$

BCE-SIGADE. (2018). Inversión directa por rama de actividad económica. Obtenido de $\quad$ https://www.bce.fin.ec/index.php/component/k2/item/298-inversiónextranjera-directa

Bénétrix, A., O’Rourke, K., \& Williamson, J. (2012). The Spread of Manufacturing to the Poor Periphery, 1870-2007. Cambridge: National Bureau of Economic Research, NBER Working Paper N. 18221.

Bonfanti, F. A. (diciembre de 2015). Análisis del modelo de industrialización por sustitución de importaciones en América Latina y en Argentina. Unac mirada hacia la realidad industrial actual en Argentina. Revista Geográfica Digital, 12(24), 1-17.

Bose, N. (2007). Public expenditure and economic growth: a disaggregated analysis for developing countries. The Manchester School, 75(5), 533-556.

Bulmer-Thomas, V. (2007). The economic history of Latin America since independece. Londrés: Cambridge University Press.

CEPAL. (2014). Información histórica - Evolución de las ideas de la CEPAL. Obtenido de

https://www.cepal.org/cgi- 


\section{Christian Paúl Naranjo Navas}

bin/getprod.asp?xml=\%2Fnoticias\%2Fpaginas \%2F4\%2F13954\%2FP13954.xml\&

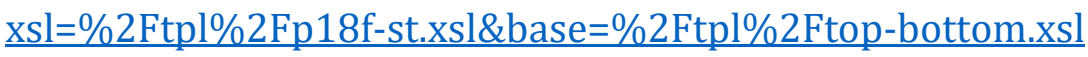

Colin, L. (2019). CEPAL and ISI: Reconsidering the Debates, Policies and Outcomes. Revista de Estudios Sociales(68), 8-26

Consejo Nacional de Planificación. (2009). Plan Nacional para el Buen Vivir 20092013. Secretaría Nacional de Planificación y Desarrollo, Quito.

Consejo Nacional de Planificación. (2013). Plan Nacional para el Buen Vivir 20132017. Secretaría Nacional de Planificación y Desarrollo, Quito.

Dieterich, H. (2005). EI Socialismo del Siglo XXI. Obtenido de https: / www.google.com/url?sa=t\&rct=j\&q=\&esrc=s\&source=web\&cd=\&cad=rja\& uact=8\&ved=2ahUKEwiE 67ZpoTqAhXSQjABHRu6CvoQFjAAegQIAhAC\&url=https \%3A\%2F\%2Fwww.rebelion.org\%2Fdocs\%2F121968.pdf\&usg=AOvVaw22bxnbD B9gNMvF2vPcW6fm

El Universo. (15 de octubre de 2011). El Impuesto a la Salida de Divisas aumentó sus recaudaciones.

Ferrer, A. (2010). La Nueva economía argentina. Obtenido de Ensayo: http://www.econ.uba.ar/planfenix/aportes/8/Ferrer/10/Ferrer\%20BAE\%20La \%20nueva\%20econom\%EDa\%20argentina.doc.

Ffrench-Davis Muñoz, R. (1983). Deuda externa y balanza de pagos de América Latina: tendencias recientes y perspectivas. Estudios Internacionales, 16(62), 281304.

Fiscalía General del Estado. (12 de mayo de 2020). Caso Soborno 2012-2016. Recuperado el 13 de junio de 2020, de https://www.fiscalia.gob.ec/caso-sobornos2012-2016/

Frieden, J. (2006). Global Capitalism. Its fall and rise in the twentieth century. New York: W. W. \& Company Ltd.

Furtado, C. (1970). Formação econômica da América Latina. RJ, Lia Editora, 1969. Obtenido de Revista de Administración de empresas: http://www.scielo.br/pdf/rae/v10n2/v10n2a12.pdf

Godínez Montoya, L., Barrios, G., \& Figueroa, E. (2015). La inversión extranjera directa en el crecimiento económico de México. En C. Santiago, A. Ayala, \& G. Almaguer, Desarrollo y tecnología. Aportaciones a los problemas de la sociedad. México, D.F.: Plaza y Valdes Editores. 


\section{Sustitución de Importaciones e Industrialización. Desde el siglo XX hasta al Socialismo del Siglo XXI, caso Ecuador}

Gonzáles Arévalo, A. L. (2010). el proceso de sustitución de importaciones en América Latina. El caso México: 1940-1980. México D.F.: Eumed.

Hofman, A. (2000). The Economic Development of Latin America in the Twentieth Century. Northampton: Edward Elgar Publishing.

Love, J. (1994). Economic ideas and ideologies in Latin America since 1930. En L. Bethell, The Cambridge History of Latin America (Vol. Volume VI).

Lupu, D., Petrisor, M., Bercu, A., \& Tofan, M. (2018). The Impact of Public Expenditures on Economic Growth: A Case Study of Central and Eastern European Countries. Emerging Markets Finance and Trade, 54(3), 552-570.

Macrotrends. (17 de May de 2019). Crude oil prices- 70 year historial chart. Obtenido de https://www.macrotrends.net/1369/crude-oil-price-history-chart

Márquez, Y. (junio de 2010). Crecimiento restringido por balanza de pagos en Brasil (1963-2005). Cuadernos de economía, 29(52).

Martínez Casas, E. A., \& Guzman, J. F. (2011). El Deterioro de los términos de intercambio: Teoría y evidencia emìrica para Colombia 1980-2010. Revista Mundo Económico y Empresarial (10), 73-88.

Mitchell, B. (1998). International Historical Statistics: The Americas 1750-1993. Londres: Macmillan Reference Ltd.

MOxLAD. (s.f.). Base de Datos de Historia Económica de América Latina MontevideoOxford. Recuperado el 2019, de Importaciones de bienes intermedios: http://moxlad.cienciassociales.edu.uy/\#

Naranjo Navas, C. P. \& Naranjo Navas, A. (2018). The dollar and the social construction of the messiah in Ecuador. En G. Nieves, \& D. Pinilla, Crecimiento económico y humano. Casos de estudio en Ecuador. Riobamba, Ecuador: Universidad Nacional de Chimborazo.

Ocampo, J. A. (2014). La crisis latinoamericana de la deuda a la luz de la historia. En J. a. Ocampo, B. Stallings, I. Bustillo, H. Belloso, \& R. Frekel, La crisis latinoamericana de la deuda desde la perspectiva histórica (págs. 19-50). Santiago de Chile: CEPAL.

Ocampo, J. A., \& Parra, M. A. (2003). Los términos de intercambio de los productos básicos en el siglo XX. Revista CEPAL (79), 7-35.

Pinto, A. (1969). La concentración del progreso técnico y de sus frutos en el desarrollo latinoamericano. En A. Bianchi, América Latina ensayos de interpretación económica. Santiago de Chile: Editorial universitaria. 


\section{Christian Paúl Naranjo Navas}

Prebisch, R. (1969). Problemas teórico y prácticos del crecimiento económico. En A. Bianchi, América Latina ensayos de interpretación económica. Santiago de Chile: Editorial universitaria.

Prebisch, R. (1998). Dependencia, Interdependencia y Desarrollo. Revista de la CEPAL (34).

Ramírez Montañez, J. (2017). El socialismo del Siglo XXI en el contexto de la Nueva Izquierda Latinoamericana. Revista Andina de Estudios Políticos, 7(2), 92-110

Santiago, F. L. (2008). La inversión extranjera directa en el crecimiento económico de México 1970-2006. Tesis de licenciatura en ciencias económicas. Universidad Autónoma Chapingo.

SENPLADES, Secretaria Nacional de Planificación y Desarrollo. (2017). Inversión para el Desarrollo. Principales Obras 2007-2017. Quito.

SENPLADES, Secretaría Nacional de Planificación y Desarrollo. (2019). Reseña histórica. Obtenido de http://www.planificacion.gob.ec/resena-historica/

Tavares, M. (1969). El proceso de sustitución de importaciones como modelo de desarrollo reciente en América Latina. En A. Bianchi, América Latina ensayos de la interpretación económica. Santiago de Chile: Editorial universitaria.

The Global Economy. (2019). Ecuador: inflation. Obtenido de https://www.theglobaleconomy.com/Ecuador/Inflation/

United Nations Educational, Scientific and Cultural Organization. (2019). UNESCO Institute for Statistics. Obtenido de Education expenditures, Ecuador: http://uis.unesco.org/en/country/ec

Vallejo Zamudio, L. E. (2003). El modelo de crecimiento hacia adentro: una interpretación del caso colombiano. Apuntes del CENES.

World Bank. (2019). The World Bank Data. Obtenido de Current health expenditure $\%$ of GDP: https://data.worldbank.org/indicator/SH.XPD.CHEX.GD.ZS?locations=EC

Recibido: $14 / 01 / 2020$

Evaluado: $20 / 02 / 2020$

Versión Final: 30/04/2020 